\title{
Design and operation experience of zero-carbon campus
}

\author{
Pan $\mathrm{Xu}^{*}$, Zebang Jin, Yuzhu Zhao, Xiaobo Wang and Haiquan Sun \\ Shandong Normal University - Lishan College, Qingzhou, Shandong, China
}

\begin{abstract}
Shandong Normal University - Lishan College is a zero-carbon campus, using the technical scheme "multiple sources of energy complementing each other, $100 \%$ utilization of renewable energy, combining concentrated demonstration with popular extension". It has built 5 distributed energy stations, including roof PV power station, solar heating water system, biomass vacuum hot water unit, natural gas (straw pyrolysis gas, biomethane) CCHP demonstration project etc. Renewable energy can provide power, heating, air conditioning and hot water for 10,000 teachers and students. The zero-carbon campus save 3,650 tce/a, and the $\mathrm{CO}_{2}$ emission reduction is 9,490 t/a. It offers great experience and is a model for the regional clean and low carbon energy usage and the realization of sustainable development.
\end{abstract}

\section{Introduction}

Energy shortage and environmental pollution are the two major problems facing the world today. The consumption of fossil fuel causes not only the emission of greenhouse gases such as $\mathrm{CO}_{2}$ but also pollutants such as dust, $\mathrm{SO}_{2}$ and $\mathrm{NO}_{\mathrm{x}}$. Renewable energy is an important means for the development of zero carbon $[1,2,3]$. Large-scale application of renewable energy can reduce carbon emissions, solve air pollution and achieve sustainable development. University should be the leader of social development and construction of zero-carbon campus plays an important leading and demonstrating role [4,5]. Zero-carbon campus is a test platform for technological innovation. It is a training base for students with sustainable consciousness and a model for leading society to achieve green, low carbon and sustainable development.

Shandong Normal University - Lishan College is an undergraduate university approved by the Ministry of Education of China. Its goal is to build a famous applied university. The school-running model is integration of production, education and research, integration of school and enterprise. The school has $400,000 \mathrm{~m}^{2}$ buildings with good insulation, floor radiation heating, and PV panels or solar collectors on roofs. The school has made breakthroughs in the field of renewable energy technology, energy saving and environmental protection, and it has established close cooperation with dozens of universities both at home and abroad. Lucy New Energy Technology Co., Ltd set up by Lishan College is a hightech enterprise focusing on new energy technology. Its products were sold well in more than 40 countries or regions. Lishan College and Lucy New Energy Company are pioneers of $\mathrm{R} \& \mathrm{D}$ and utilization of new energy technologies in China and have built the zero-carbon campus of large-scale application of renewable energy. There are thousands of visitors from all over the world every year.

\section{Technical schemes of zero-carbon campus}

\subsection{Design Concept}

Shandong Normal University - Lishan College located in Yunmen mountain scenic spot, undertaking the responsibility of protecting environment. As for school construction, we strictly followed green development concept and abided by the law of developing circular economy, rejecting highly polluting fossil fuels such as coal, and applying renewable energy to build a zerocarbon campus.

The design concepts of the zero-carbon campus include:

(1) The application of renewable energy on large-scale to achieve zero carbon emissions.

(2) According to local conditions, using distributed energy technologies to achieve energy selfsufficiency.

(3) Energy cascade utilization and efficient utilization of low grade heat energy.

(4) Using the whole life cycle to analyze and design.

(5) Not to store energy as far as possible and seamless docking with the grid.

(6) To realize the closed loop chain of ecological cycle.

\subsection{New energy technology for campus}

The campus is densely populated, and the energy consumption is large [1]. Owing to stable and concentrated demand of electricity, heat, air conditioning and hot water, it is quite suitable for developing distributed energy system. Campus buildings are basically multi-storey, suitable for the application of solar energy. Generally speaking, the campus is rich in biomass resources, including agricultural and forestry waste, kitchen waste and so on.

\footnotetext{
Corresponding author: xpan51@126.com
} 
The rational use of biomass energy can not only change waste into treasure, but also protect the environment. According to the geographical location, energy demand and energy price of Lishan College, the renewable energy and new energy for application are analyzed as follows.

1) Solar energy, including solar absorption air conditioning technology, solar PV air conditioning technology, solar hot water, solar street lamps, and so on.

2) Biomass energy, including direct combustion of straw pellet fuel for heating, biomass pyrolysis gas CCHP, biomethane CCHP and so on.

3) The cascade utilization of energy. Lishan College has built natural gas (straw pyrolysis gas and biomethane) CCHP demonstration project.

4) Geothermal energy. In order to solve the problem of imbalance between heat and heat load of ground source heat pump, geothermal energy plus solar thermal storage technology can be adopted, which can not only realize geothermal energy recycling, but also store solar energy.

5) Low grade heat energy utilization. With continuous deepening of energy saving work, effective utilization of low grade heat energy resources has become the key and difficult point of energy saving work. The low-grade heat utilization technology suitable for the school includes the sewage source heat pump, the air source heat pump and the high temperature flue gas depth recovery technology.

\subsection{Energy solutions}

Lishan College adopts the technical scheme of "multiple sources of energy complementing each other, $100 \%$ utilization of renewable energy, combining concentrated demonstration with popular extension" to build a zerocarbon campus. Electricity, heat, air conditioning, and hot water are all from clean renewable energy

Table 1. The utilization of various new energy

\begin{tabular}{|c|c|c|c|c|c|c|}
\hline & \multirow{2}{*}{$\begin{array}{ll}\text { Energy Utilization } \\
\text { Equipment }\end{array}$} & \multirow[t]{2}{*}{ Specifications } & \multicolumn{4}{|c|}{ Energy Use Form } \\
\hline & & & Electricity & Heating & Cooling & Hot water \\
\hline \multirow{4}{*}{ Solar } & $\begin{array}{l}\text { Solar absorption air } \\
\text { conditioning system }\end{array}$ & $5180\left[\mathrm{~m}^{2}\right]$ & $x$ & $\sqrt{ }$ & $\sqrt{ }$ & $\sqrt{ }$ \\
\hline & Solar PV Panel & $2[\mathrm{MW}]$ & $\sqrt{ }$ & $\sqrt{ }$ & $\sqrt{ }$ & $\sqrt{ }$ \\
\hline & $\begin{array}{l}\text { Solar bath hot water } \\
\text { system }\end{array}$ & $9600\left[\mathrm{~m}^{2}\right]$ & $x$ & $x$ & $x$ & $\sqrt{ }$ \\
\hline & $\begin{array}{ll}\begin{array}{l}\text { Solar boiled } \\
\text { system }\end{array} & \text { water } \\
\end{array}$ & $220\left[\mathrm{~m}^{2}\right]$ & $x$ & $x$ & $x$ & $\sqrt{ }$ \\
\hline \multirow{3}{*}{ Biomass } & Pellet vacuum boiler & $2 \times 7[\mathrm{MW}]$ & $\sqrt{ }$ & $x$ & $x$ & $x$ \\
\hline & Pyrolysis gas CCHP & $1[\mathrm{MW}]$ & $\sqrt{ }$ & $\sqrt{ }$ & $\sqrt{ }$ & $\sqrt{ }$ \\
\hline & Biomethane CCHP & $35[\mathrm{~kW}]$ & $\sqrt{ }$ & $\sqrt{ }$ & $\sqrt{ }$ & $\sqrt{ }$ \\
\hline Wind & Wind power generator & $20[\mathrm{~kW}]$ & $\sqrt{ }$ & $x$ & $x$ & $x$ \\
\hline \multirow{3}{*}{$\begin{array}{l}\text { Low grade } \\
\text { heat }\end{array}$} & Air source heat pump & $22240[\mathrm{~kW}]$ & $x$ & $\sqrt{ }$ & $\sqrt{ }$ & $x$ \\
\hline & $\begin{array}{l}\text { Wastewater source } \\
\text { heat pump }\end{array}$ & $350[\mathrm{~kW}]$ & $x$ & $\sqrt{ }$ & $x$ & $x$ \\
\hline & $\begin{array}{l}\text { Ground source heat } \\
\text { pump }\end{array}$ & $700[\mathrm{~kW}]$ & $x$ & $\sqrt{ }$ & $\sqrt{ }$ & $x$ \\
\hline Natural gas & $\mathrm{CCHP}$ & $200[\mathrm{~kW}]$ & $\sqrt{ }$ & $\sqrt{ }$ & $\sqrt{ }$ & $\sqrt{ }$ \\
\hline
\end{tabular}

\section{Construction process of zero-carbon campus}

\subsection{Application of solar energy air-conditioning technology}

Solar air conditioning's seasonal matching is good. The hotter the temperature, the greater demand for air conditioning, and the better condition of the solar radiation and the greater capacity of the solar refrigeration. Solar air conditioning includes solar thermal absorption air conditioning system and solar PV air conditioning system. These two forms of solar air conditioning are used in the Lishan College. Lishan college has installed $5800 \mathrm{~m}^{2}$ solar collector system to drive $\mathrm{LiBr}$ absorption chiller to achieve three kinds of energy supply, such as cooling in summer, heating in winter, hot water in four seasons. The system saves more than $60 \%$ energy consumption. It has installed $2 \mathrm{MW} \mathrm{PV}$ power station. The air source heat pump driven by PV power is used to heat the students' apartment in winter and to provide cool air in summer. During theholiday period, solar PV power is sold to grid. In addition to the solar air conditioning system, it has other forms of solar applications. $9600 \mathrm{~m}^{2}$ solar hot water system provides bathing hot water for the students. 2000 metal heat pipe solar vacuum tubes provide $5 \mathrm{t} / \mathrm{d}$ boiled water, and the biogas as an auxiliary energy. The school has also installed more than 200 solar street lamps and so on. 


\subsection{Demonstration project of crop straw heating}

$2 \times 7 \mathrm{MW}$ biomass vacuum hot water units heating $250,000 \mathrm{~m}^{2}$ building. The heating equipment is the patent product of Lishan College. Crop straw is used as fuel for the biomass vacuum hot water unit, and the thermal efficiency is up to $95 \%$, and the emissions conform to China's ultra-low emission standards. Biochar slowrelease fertilizer produced with straw ash to promote crop growth. It has realized the comprehensive utilization and ecological cycle chain of "straw - fuel heating - fertilizer - crop (straw)".

\subsection{Demonstration project of biogas CCHP}

Lishan Colleg has undertaken and completed the national high-tech $R \& D$ program of China (863 program) "the demonstration project of the biomethane CCHP". There are three tasks in this project: (1) The organic wastes are efficiently converted into biogas. (2) Research and development of high efficiency biogas generator. (3) Optimize the control system of CCHP. This project realizes the organic waste harmless treatment, biogas energy cascade utilization, ecological utilization of fermentation residue. In addition to the CCHP with biogas as fuel, the school also has $1 \mathrm{MW}$ biomass pyrolysis gas CCHP, $200 \mathrm{~kW}$ natural gas CCHP and $50 \mathrm{~kW}$ diesel CCHP system. The energy utilization rate of CCHP is above $85 \%$.

\subsection{Air source heat pump}

$7,000 \mathrm{~kW}$ air source heat pumps have been installed in $100,000 \mathrm{~m}^{2}$ of buildings for cooling, heating and hot water. The heat pump combined with the small temperature difference heat transfer end can further improve the COP and improve the comfort of the room.

\subsection{Distributed energy stations}

At present, Lishan College has built 5 major distributed energy stations, including $2 \mathrm{MW}$ roof PV power station, $1,5000 \mathrm{~m}^{2}$ of solar hot water system, 2 sets of $7 \mathrm{MW}$ biomass vacuum hot water unit, $200 \mathrm{~kW}$ natural gas CCHP demonstration project, $1 \mathrm{MW}$ straw pyrolysis gas CCHP demonstration project, $35 \mathrm{~kW}$ biomethane CCHP demonstration project, and 200 solar street lamps, dozens of air source heat pumps, solar absorption air conditioning system, combined compression and absorption type chiller, ground source heat pump + solar seasonal storage system etc. The school's electricity, heat, air conditioning and hot water are all from renewable energy and new energy.

\section{Operational analysis}

\subsection{Energy saving and environmental benefit analysis}

The advantages of renewable energy are low carbon and clean. Lishan College attaches great importance to energy-saving work, taking technological, management, and other measures to achieve energy-saving, so the overall energy consumption is small. In 2016, the overall number of people in school is 9,640, the power consumption was $2,151,355 \mathrm{kWh}$. The school's PV power plant generates more than $2,000,000 \mathrm{kWh}$ electricity per year. Supply heating for $400,000 \mathrm{~m}^{2}$ buildings depends on crop straw, generator waste heat and air source heat pump. The bath hot water is all provided by the solar heat collector system and the air source heat pump. According to the calculation, the renewable energy and energy saving equipment of the school save 3,650 tce/a, and the $\mathrm{CO}_{2}$ emission reduction is 9,490 t/a.

\subsection{Economic analysis}

Economic benefits are the biggest restrictive factors in the application of new energy and renewable energy. The initial investment in large-scale application of renewable energy is large. A total of $\$ 14.4$ million is invested in renewable energy and energy saving equipment in Lishan College. Among them, the investment of $15,000 \mathrm{~m}^{2}$ solar collector and $700 \mathrm{~kW}$ absorption chiller is $\$ 4,500,000$. The $2 \mathrm{MW} \mathrm{PV}$ power station and 200 solar street lamps were invested $\$ 2,900,000$. The total investment was $\$ 2,810,000$ of biomass energy utilization equipment. Air source heat pump investment of $\$ 650,000$, sewage source heat pump investment of $\$ 260,000$, ground source heat pump investment of $\$ 580000$, low grade heat utilization of a total investment of $\$ 1,490,000$. A total of $\$ 1,800,000$ is invested in the CCHP. Wind power, EV and LED are invested in $\$ 900,000$. In recent years, the Chinese government has made great efforts to support the new energy industry. Generally speaking, the investment recovery period of renewable energy project is within 8 years. 


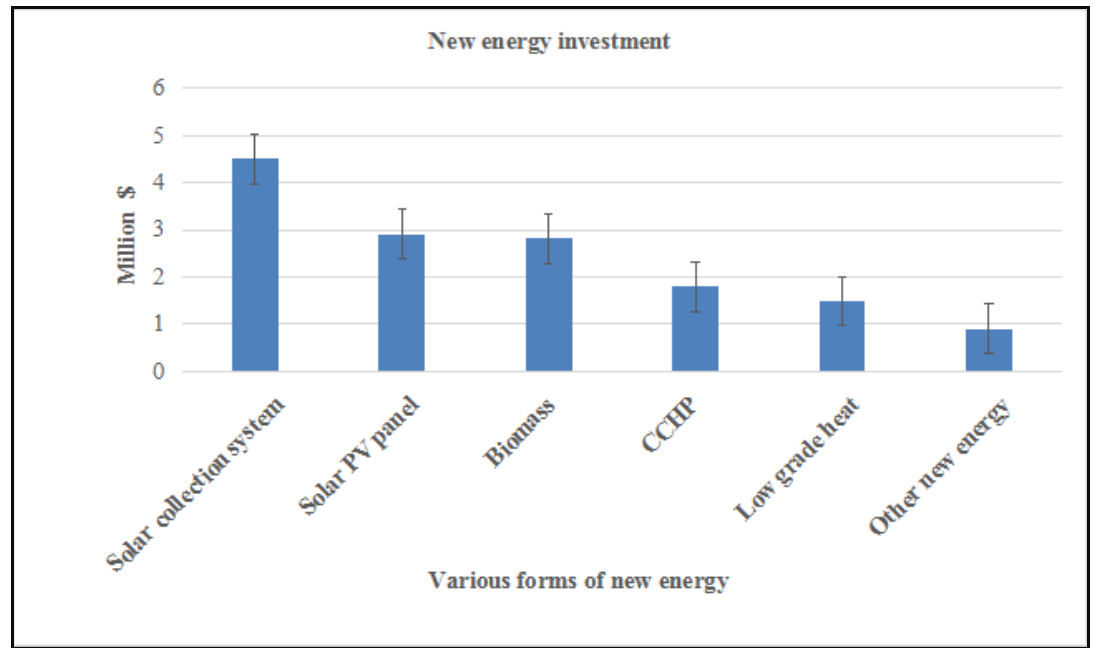

Fig. 1. New energy investment of Lishan College

\subsection{Problems in operation}

Renewable energy provides comfortable life for 10,000 teachers and students. But there are still some problems in the actual operation of each energy station, and it needs to be improved in the later period. The solar energy collector system needs to further reduce the energy consumption and optimize the operation of the circulating pump. In the spring and autumn seasons, part of the heat energy of the solar absorption air conditioning system is still not used. The price of natural gas is high, the electricity price of the school is low, and the application of the gas CCHP on campus is not good. At present, each energy station in the school is relatively independent, and the complex multiple energy flow network needs to be further optimized to improve the economic efficiency. We intend to establish an Integrated Energy Management System (IEMS) to achieve "multiple energy complementary, source, network, and load can be coordinated", and in the end it can realize maximized benefits.

\section{Conclusion}

The zero-carbon campus built by renewable energy, energy saving and environmental protection technology in Shandong Normal University - Lishan College is running well, providing clean and low-carbon energy for all teachers and students, basically realizing energy selfsufficiency, and continuously improving the distributed energy system in actual operation. The zero-carbon campus offers great experience and is a

model for the regional clean and low carbon energy use and the realization of sustainable development.

\section{References}

1. O. Opel, N. Strodel, Climate-neutral and sustainable campus Leuphana University of Lueneburg. Energy. 141, pp. 2628-2639 (2017)

2. Hongbo Liu, Xinghua Wang, The ecological footprint evaluation of low carbon campuses based on life cycle assessment: A case study of Tianjin, China. Journal of Cleaner Production. 144, pp. 266278 (2017)

3. Dimitrios Hasapis, Nikolaos Savvakis, Design of large scale prosuming in Universities: The solar energy vision of the TUC campus, Energy and Buildings. 141, pp. 39-55

4. Hongwei Tan, Shuqin chen, Development of green campus in China, Journal of Cleaner Production, 64, pp. 646-653

5. Magnus Bonde, Jill Ramirez, A post-occupancy evaluation of a green rated and conventional oncampus residence hall. International Journal of sustainable Built Environment. 4, pp.400-408 (2015) 